\title{
ALFOMBRAS DE ALCARAZ EN CONTEXTOS PALACIEGOS: DE ISABEL I A LA CASA DE ALBA. NUEVAS APORTACIONES ${ }^{1}$ ALACARAZ RUGS IN PALATIAN CONTEXTS: FROM ISABEL I TO THE HOUSE OF ALBA. NEW CONTRIBUTIONS
}

\author{
Carlos Ayllón Gutiérrez \\ Instituto de Estudios Albacetenses
}

\section{Introducción}

Nunca se ha ponderado lo suficiente el hecho de que las alfombras confeccionadas en Alcaraz fueron las de mayor calidad de cuantas se elaboraron en toda España entre los siglos XV y XVIII y las más renombradas de toda la Europa cristiana, si bien es sabido que allende el Pirineo no se usaba la confección alfombrera, de vieja raigambre oriental. Incluso existen expertos - Shepherd, Partearroyo - que sospechan que los célebres modelos turcos de tipología Holbein imitaron a los alcaraceños, poniendo en tela de juicio la idea dominante de que eran los diseños y técnicas turcos los que fueron adaptados en los talleres andalusíes a través del comercio veneciano (Sherrill). ${ }^{2}$ En todo caso no estamos exagerando: el catálogo referente a la Exposición de Alfombras Antiguas Españolas, celebrada en Madrid durante la primavera de 1933, no dejaba lugar a dudas, pero pese a la aparición de publicaciones posteriores relativas a las alfombras españolas en general y las alcaraceñas en particular, todavía no ha arraigado entre nosotros lo suficiente la significación de tales objetos.

En realidad, cuando nos referimos a las alfombras de Alcaraz, cabe aludir con más propiedad a las confeccionadas en esta ciudad y en los pequeños núcleos santiaguistas de Socovos, Férez, Letur y sobre todo Liétor, elaboradas con una técnica tan similar que, cuando faltan rasgos que delatan expresamente el origen de las piezas, resulta prácticamente imposible diferenciarlas. De ahí que de hecho en muchas ocasiones a tales alfombras de origen dudoso se las denomina "de tipo Alcaraz" o simplemente "de Alcaraz". Cabe apuntar que la numerosa población mudéjar y luego morisca en las tierras de la Orden de Santiago contiguas al alfoz alcaraceño, ayuda a explicar su prolífica confección de alfombras, de uso imprescindible para el rezo cotidiano en los hogares musulmanes.

En todo caso, la producción alfombrera de las tierras hoy encuadradas en la provincia de Albacete hay que remontarla a la época andalusí. La Șürat al-'Arḍ (La configuración de la Tierra) de Ibn Hawqal (978) señala:

* E-mail: ayllongut@hotmail.com 
fuera de Oriente las alfombras anudadas (busut mahfur) se producen en alÁndalus en el distrito de Murcia, en la misma ciudad de Murcia, en Tantalyya (Chinchilla) y en Alsh (Elche), y eran alfombras similares a las mejores y más caras alfombras de la producción armenia. ${ }^{3}$

Elogios de autores árabes a las alfombras confeccionadas en talleres de esta zona continuarían en los siglos sucesivos.

Sería una tarea ingente intentar recopilar todas las alusiones dispersas por estudios y archivos acerca de las piezas de Alcaraz y su entorno geográfico. En cuanto a los principales trabajos específicos, cabe una mención obligada a los títulos de José Sánchez Ferrer, que nos han permitido conocer de forma suficientemente detallada la historia, las implicaciones socioeconómicas de la manufactura, los tipos y naturaleza de la urdimbre y otros detalles y rasgos formales propios de este tipo de objetos. Digno de destacar es su reciente estudio Alfombras de Alcaraz y de Liétor, en el que hace una puesta al día de casi todo cuanto se ha publicado sobre el tema que nos ocupa y al que contribuye con abundante material inédito. ${ }^{4}$

Entendemos, no obstante, que es procedente llamar la atención sobre algunos ejemplos de alfombras no mencionados en dicha obra y encontrados en archivos y en obras de menor difusión. De este modo alcanzaremos a obtener una imagen más precisa de la relevancia de tales piezas en las sociedades que les dieron uso. ${ }^{5}$ Ya el catálogo de la citada muestra de 1933 daba cumplida cuenta de la presencia de alfombras procedentes de los talleres de Alcaraz engalanando los más señalados palacios de los reinos hispanos. Lo mismo cabe decir de la posterior y numerosa bibliografía, dentro de la cual la prolífica producción de José Luis Barrio Moya (que no cabría desgranar en este reducido trabajo) alude frecuentemente a la abundancia de poderosos personajes que tuvieron en su posesión alfombras de Alcaraz, lo cual habrá de ser tenido en cuenta cuando haya que volver a acometer un estudio exhaustivo de estas piezas. ${ }^{6}$ Fue tal el prestigio alcanzado por estas manufacturas que algunas alfombras y tapetes de origen distinto se pretendieron hacer pasar por alcaraceños. ${ }^{7}$ Pero al ser innumerables las familias potentadas que tuvieron entre sus bienes alfombras de procedencia alcaraceña, he querido detenerme únicamente en los ejemplares que cubrieron los suelos de ciertos palacios en que habitaron algunos de los linajes nobiliarios más poderosos, así como los de diferentes miembros de la familia real castellana - y después de la monarquía hispánica-, al igual que otros espacios a ella vinculados. Este fenómeno no tardaría en hacerse extensivo a algunas de las principales mansiones del Nuevo Mundo. ${ }^{8}$

Multitud de alfombras pueblan la documentación regia de la época. Aunque en ocasiones no hay mención a su origen, fue un hecho habitual recurrir a las alcaraceñas a la hora de guarnecer las estancias reales y de los infantes. De ahí que, en un reciente artículo, Aurelio Pretel recordara las que habían servido como obsequio a diferentes miembros de la casa real a finales del siglo XV y en las primeras décadas del XVI. ${ }^{9}$ A este selecto grupo de clientes cabe añadir catedrales como la de Toledo y numerosas casas de la nobleza española. En este sentido, refiere Ramírez de Lucas que ya con anterioridad el conde de Plasencia Álvaro de Zúñiga tenía al menos tres alfombras de "Litur", inventariadas en 1468, por lo que muy pronto la zona había empezado a proporcionar producción de calidad para las élites caste- 
llanas. ${ }^{10}$ Recordemos, por lo demás, que esta época coincide con la etapa de actividad del Maestro de la Sisla, que reproduce una de estas alfombras de tipología alcaraceña en su Anunciación del Museo del Prado, un indicio más del especial protagonismo que tuvieron en tal periodo.

\section{Los nuevos ejemplos documentados. La familia real.}

Alfombras de Alcaraz se hallaban entre los bienes de Isabel I, así como de numerosos descendientes suyos. Se emplearon para cubrir los suelos de la cámara, la sala y la capilla de la reina Católica y de otros miembros de su familia, y de igual modo se usaron en sus estrados, escenarios fúnebres y recintos sepulcrales. La primera ocasión en que se evidencia la posesión de este tipo de bienes en el entorno de los monarcas se sitúa a lo más tardar en 1490 , cuando ya se habían adquirido en la ciudad treinta y seis alfombras por 170.000 maravedíes para la infanta Isabel. Sin duda iban dirigidas a dotarla para su matrimonio, que tendría lugar el 3 de noviembre de ese año con el príncipe Alfonso de Portugal. Para su adquisición se hizo el encargo al alcaraceño Diego de Buitrago, a quien se le abonaron las mencionadas cantidades en febrero de 1491. ${ }^{11}$ En este punto, cabe señalar que Buitrago - hidalgo de origen judío y perteneciente a una de las familias más significadas de la oligarquía de la ciudad - también era escribano de rentas en el amplio arcedianazgo de Alcaraz, además de un frecuente fiador. Así, su posición económica le permitiría ejercer de promotor de las propias manufacturas en una suerte de financiador adelantado del Kaufsystem en la comarca. Sin un respaldo de gentes como Diego de Buitrago, difícilmente hubiera podido prosperar la artesanía de alfombras en Alcaraz. Poco después, en enero de 1492, al recibir la ciudad la noticia de la conquista de Granada, los oficiales concejiles quisieron obsequiar a los monarcas con una alfombra de los talleres de Alcaraz, además de hacerles llegar un montante de 6.400 maravedíes. ${ }^{12}$

Sancho de Paredes, camarero mayor de Isabel la Católica desde 1498, al registrar minuciosamente los balances de la casa de la reina, consignó la progresiva adquisición de lotes de alfombras con procedencia alcaraceña, llegando a contabilizar hasta cincuenta y ocho ejemplares, además de otro puñado de alfombras turcas y algunas otras de cuyo origen no da cuenta y que quizá hubiera que añadir a los conjuntos de Alcaraz. De todas las referidas, al menos cuarenta y ocho presentaban en mayor o menor abundancia y tamaño motivos de ruedas, tan comunes en las piezas que nos atañen. ${ }^{13}$

En 1498, Beatriz Cuello, suegra de Paredes y camarera de la reina junto a su marido Martín Cuello, compró otra alfombra alcaraceña - que en 1505 unos mercaderes (Alonso de Toledo y Alonso de Pina) tasaron en la ciudad de Toro para su venta, en 12 ducados (4.500 maravedíes)—, en un momento en que se está realizando el traspaso de funciones de administración de la cámara de la reina, entre el matrimonio Cuello y su yerno Sancho de Paredes. En agosto de 1498, hallándose en Zaragoza Sancho de Paredes y Beatriz Cuello, recibieron de los arrendadores de las rentas reales de Alcaraz doce alfombras de medidas desiguales, seis de las cuales estaban decoradas con ruedas. Una de las mayores fue entregada en Granada en octubre de 1501 a Juana de la Torre, ama del príncipe Juan. Suero de Cangas, entregó 
en 1503 otras tres de nuevo a Beatriz Cuello: una para sí, otra para Martín Cuello y otra que iría destinada a la sepultura de doña Beatriz; y aparte se dio una más a Cristóbal de la Concha. Así, con frecuencia la posesión de alfombras por parte de los reyes tuvo un carácter temporal, pues derivó en este tipo de cesiones posteriores a terceros, cuando no en reventas o en limosnas a entes eclesiásticos.

Asimismo, una alfombra de Alcaraz de cuatro ruedas fue donada al monasterio de Santo Domingo de Portaceli de Sevilla; mientras que en esta misma ciudad otra sin ese tipo de elementos decorativos fue entregada en 1500 a Inés Banegas, ama de la infanta Catalina, para que a su vez la diese a Isabel de Solís, madre de los infantes nazaríes Sa'ad y Nasr.

La compra de alfombras de Alcaraz resultó especialmente intensa en Granada en septiembre de 1500. El día 20 de ese mes los administradores de la casa de la reina adquirieron por medio de Aldonza Suárez — camarera de la infanta María y esposa de Juan de Calatayud, a su vez camarero del príncipe Juan - tres unidades que se ofrecieron en enero de 1501 a fray Lope de Úbeda, guardián del monasterio franciscano de San Luis "cabe Granada" (esto es San Luis de La Zubia, fundado pocos meses atrás) para uso de los religiosos de la comunidad, aunque se hallaban "viejas e rotas por algunas partes". Al día siguiente de su adquisición se obtuvieron nada menos que otras diecinueve alfombras de igual procedencia, que fueron puestas en custodia de la citada Aldonza Suárez. Para aquellas fechas, María ya estaba prometida para una inminente boda con el rey portugués Manuel el Afortunado, por lo que las alfombras irían destinadas a sus futuros aposentos como monarca consorte del vecino reino. Se trataba de un conjunto de piezas de grandes dimensiones y vistosa decoración con las típicas ruedas de los talleres alcaraceños. Entre todas ellas llaman la atención varias que superan las seis varas de largo (unos $5 \mathrm{~m}$ ), una de ellas de labor "naranjada" y otra decorada con unos lazos verdes "e en medio dellos una lauor en que ay seys paneles en cada una"14

Ciertamente, la dotación de las infantas con alfombras será una constante en la familia real. En 1501 se registró la recepción de otro gran conjunto de alfombras de Alcaraz, por mediación de Gonzalo Fernández de Córdoba en nombre del tesorero Alonso de Morales. Fueron entregadas a Sancho de Paredes y a Isabel Cuello en Granada el 20 de marzo de ese año, poniéndose dos meses después en posesión de Juan de Cuero, camarero de Catalina de Aragón para servicio de la infanta. Comprometida en matrimonio con el príncipe de Gales, la salida de Catalina hacia Inglaterra era inminente. El lote (Véase Apéndice documental) estaba integrado por nueve alfombras de 20 palmos de largo, seis de 25, cuatro de 30 palmos y una más de 40. Ignoramos su anchura, pero la descripción que tenemos de ellas es algo más detallada que en el caso de las anteriormente mencionadas y nos ayuda a conocer el cromatismo, diseño y dimensiones de las mejores alfombras que en el cambio de centuria se confeccionaban en la comarca.

Hay que señalar en este sentido que en 1494 la reina Isabel ya había hecho enviar, medianas y algo raídas, tres alfombras de origen alcaraceño a Madrid para uso de la infanta Catalina. Por entonces la familia real ya vivía una auténtica fiebre de adquisición de este tipo de bienes, pues ese mismo año la reina hizo entregar a su contino Diego Cano catorce alfombras de Alcaraz 
que llevó a Tordesillas Diego de Gaona. Siete años después, considerando que las piezas ya estaban viejas, la reina pedía a Cano que diera tres de ellas al camarero Sancho de Paredes para que las emplease en cubrir las arcas de la cámara de la reina. Por otra parte, en noviembre de 1497 Isabel I mandó entregar a Hernando de Mercado — veedor de su despensa- seis alfombras medianas de Alcaraz, nuevas aunque algo "raydas", para que las depositase en el monasterio de Santo Tomás de Ávila, donde estaba sepultado el príncipe Juan, poniendo de igual modo una alfombra nueva de Letu (sic, por Letur más que Liétor, y descrita como "de las de Alcaraz") en manos de Alonso Fernández del Rincón, "sacristán de las señoras infantes", para servicio de éstas. Finalmente, la reina dispuso entregar en mayo de 1499 a Alonso de la Reina, repostero de estrados de la infanta Catalina, otra alfombra de Alcaraz mediana y nueva con destino al estrado de las infantas. ${ }^{15}$

De acuerdo con un inventario de 1504, Sánchez Ferrer indica que los Reyes Católicos disfrutaron en los Alcázares de Segovia de unas alfombras de Liétor y otras de Letur, además de “...ocho almohadas de Alcaraz viejas, rotas, vacias". A ese mismo año pertenece una referencia, entre los bienes de Isabel la Católica, a una alfombra de Liétor con decoración de ajedrezado y estrellas de seis puntas. Recordemos que este motivo estrellado aparece en una alfombra con denominación Alcaraz y diseño mudéjar conservada en el Museo Nacional de Artes Decorativas de Madrid. ${ }^{16}$

También se hallaron alfombras de la sierra de Alcaraz entre los bienes de los hijos de Fernando e Isabel. Es cierto que algunas serían simple herencia recibida de sus progenitores, como muy probablemente ocurriera con los bienes de la reina Juana I, entre los que se encontraba un abundante conjunto de estas alfombras. Por ejemplo, se sabe que poseyó una "que tenia el canpo verde e a los cauos vnos arboles con vnos perros en medio dellos, de quarenta palmos e ancho bara e media". Sin duda estos motivos de los extremos se corresponden con los que aparecen en la pieza del monasterio de Santa Clara de Medina del Pomar, visibles en la lámina IV de la última obra de Sánchez Ferrer. ${ }^{17}$

También los consortes de esta generación recibirían alfombras como obsequio. Con motivo de los esponsales del príncipe Juan, recién erigido en señor de Alcaraz, el concejo de esta ciudad convino en regalar a su prometida, Margarita de Austria, en abril de 1497 otro lote compuesto de cinco alfombras de treinta palmos, otros cinco de veinticinco palmos y cinco más de veinte, a lo que se añadieron unas bolsas artesanales. Un conjunto, en definitiva, verdaderamente valioso, al que se unió otro más que los Reyes regalaron a doña Margarita, si bien su origen no se especifica. ${ }^{18}$

$\mathrm{Al}$ iniciar Carlos I su reinado y su estancia en España, el concejo de Alcaraz acordó enviarle mensajeros y procuradores para declararle su obediencia y de paso pedirle la confirmación de sus privilegios y asegurarse ciertas sentencias en favor del consistorio. Añade Sánchez Ferrer a tal efecto que, en señal de acatamiento y saludo de los alcaraceños, se enviarían doce bolsas y doce alfombras para que fueran entregadas al rey o bien a su hermana Leonor de Austria, además de otras doce bolsas y seis alfombras en gratitud por la confirmación de sus privilegios. ${ }^{19}$ Por lo demás, a finales del siglo XIX Sir William Stirling-Maxwell consiguió documentar cuatro alfombras turcas y tres de Alcaraz entre los objetos que el emperador Carlos V mantenía en su retiro de Yuste. ${ }^{20}$ 
A finales de mayo de 1526, al ser nombrada la emperatriz Isabel señora de Alcaraz, el concejo decide obsequiarla con dos docenas de bolsas y doce de alfombras "muy finas e de buena mano para que se enbien por presente a la Emperatriz nuestra sennora", mientras los enviados le suplicaban que respetase los privilegios de la ciudad. ${ }^{21} \mathrm{El}$ procedimiento, pues, se repite. Dos meses después, Isabel de Portugal cursó una carta a los alcaraceños con la que les agradecía el presente que le brindaran y les prometía mantener en pleno vigor los usos y libertades de que disfrutaban. La contaduría de la casa de la infanta Catalina de Austria ya había desembolsado dos años antes la suma de 1.600 maravedíes por una alfombra alcaraceña, ${ }^{22}$ de donde cabe inferir que la llegada de la dinastía Habsburgo a la Corona hispana facilitaría cierta difusión de las manufacturas alcaraceñas en tierras centroeuropeas.

Por otra parte, al ser muy numerosas las aportaciones documentales recogidas por Sánchez Ferrer sobre las alfombras que estuvieron en las estancias de Felipe II y sus sucesivas esposas, aquí añado únicamente algunas que escaparon a su atención. Los inventarios de este monarca registran en Aranjuez tasada en 20 ducados

una alfombra de las de Alcaraz, de lana de diversas colores, que en el campo tiene cinco bandas sesgadas de ruedas pequeñas y todo lo demás del campo hecho de las dichas vandas y ruedas, con tres cenefas a las cabezeras y dos a los lados; tiene siete baras y media de largo y dos y cinco sesmas de ancho.

También, tasada en 200 reales, se refiere una pieza alcaraceña "de lana de diversos colores (...), el campo amarillo", de cinco varas y media de largo, y tres de ancho, para instalar en la escalinata delante del altar de la Capilla Real de Açeca. Por último, en el lugar de El Pardo lució

una alhombra de lana de verde y más verde, colorado y amarillo, de plumages y penachos, que tiene dos baras y dos tercias de largo, y de ancho bara y dos tercias, de las que se hicieron en Alcaraz, tasada en doze ducados. ${ }^{23}$

Un ejemplar este que recuerda por su descripción algunas de las alfombras alcaraceñas que el rey Felipe II donó al monasterio de El Escorial. ${ }^{24}$

Cabe, además, la posibilidad de que otro lote de alfombras fueran adquiridas en tiempos de Felipe IV por Diego de Silva Velázquez para ornato del Palacio del Buen Retiro, pues en los tiempos en que el genial pintor anduvo obteniendo obras para su decoración, también compró algunos bienes en la almoneda del inquisidor Alonso de Salazar y Frías. De este modo el 3 de febrero de 1636 se remató

en Diego Velázquez, pintor de Su Majestad, un tapete de Alcaraz fino de dos varas y media de largo y vara y media de ancho, y otro tapete de Alcaraz blanco y negro viejo y más otro tapete de Alcaraz amarillo y verde. Todos los tres los llevó en cien reales de vellón.

Sin embargo, no descartemos que estas u otras alfombras alcaraceñas las adquiriese Velázquez para sí, pues cuando en octubre de 1655, tras haber fallecido su hija Francisca — esposa de Juan Bautista del Mazo- y hacerse 
la tasación de los bienes de la mujer, se consignó otra alfombra de Alcaraz de çinco varas y un tercio de largo, y dos y media de ancho, que se tasó en 350 reales. ${ }^{25}$ Asimismo, hubo algunas alfombras entre los objetos de Carlos II, Felipe V y Fernando VI, aunque su menor protagonismo evidencia que, a lo largo de esta época, la manufactura alcaraceña había entrado en franco declive.

También las altas instituciones pusieron sus ojos en tan preciados objetos. No sólo la Inquisición en sus años iniciales se incautó en la ciudad de diversas alfombras como preciado cobro de sanciones. ${ }^{26}$ También el Consejo de Indias emitió en 1570 un mandamiento al receptor Antonio de Cartagena para que comprase dos alfombras alcaraceñas por 9.187 maravedíes para uso del propio Consejo. ${ }^{27}$

La adquisición de alfombras de Alcaraz por parte de la familia real desde finales del siglo XV, provocó que los distintos elementos aristocráticos, en su afán por emular a los monarcas, codiciaran estos objetos para sus palacios, aunque ya vinieran hallándose piezas de esta naturaleza en sus aposentos. La Casa de Aguilar (incorporada con posterioridad a la de Medinaceli) poseyó en la baja Edad Media algunas de estas alfombras, como detectó en su día Quintanilla Raso. De acuerdo con un inventario realizado en 1518, tras el fallecimiento de Pedro Fernández de Córdoba, primer marqués de Priego, la familia atesoraba dos alfombras grandes, de cuarenta palmos, "de las de Alcaraz", valoradas en 22.000 maravedíes; cuatro alfombras de esta procedencia, de veinte palmos tasadas en 12.000 maravedíes, y otras dos alfombras "finas" alcaraceñas de quince palmos (3.000 maravedíes), a las que se añadían otra veintena de variadas alfombras cuyo origen no quedó especificado en el inventario. ${ }^{28}$ Pero a falta de más datos sobre las cantidades que la protoburguesía comercial de la ciudad ingresaba por la exportación de alfombras, estos ejemplos nos ayudan a inferir lo que tales bienes supusieron para la sociedad local, tanto en cuantía monetaria como en valor cualitativo. No en vano, a finales de la centuria del quinientos, y dos años antes de las apreciaciones formuladas por el cronista Florián de Ocampo (quien se admiraba de la "primeza de las alhombras" de Liétor y Alcaraz), fray Jerónimo Román, al referir las profesiones que destacaban en diferentes poblaciones de Castilla, afirmaba "como oy en Segouia se tratan las lanas, en Valencia, Murcia y Granada la seda, en Salamanca los reposteros, en Alcaraz las alhombras". ${ }^{29}$

\section{En los palacios de la aristocracia.}

Asimismo, entre las más elevadas dignidades del reino, nos consta que en 1613 el duque de Lerma cedió al monasterio de San Blas de Lerma para su dotación fundacional un conjunto de alfombras, todas ellas de Alcaraz,

de colorido brillante y apreciadas labores: para el altar mayor era una grande, de seis varas, y otra de la misma dimensión para el coro alto; dos medianas, para los altares colaterales, y cuatro alfombrillas para las capillas del claustro alto y bajo. ${ }^{30}$

Sin duda constituían parte del mismo lote que el valido del rey había adquirido el año anterior. Ciertamente, por aquel tiempo los inventarios del 
palacio ducal de Lerma registraban, entre numerosas alfombras de variado origen, una buena colección de Alcaraz, a saber: una blanca y negra, de casi cuatro varas de largo y dos varas de ancho; "tres alombrillas viejas" de dos varas y media de largo cada una, y de ancho vara y cuarta; otras dos alfombras con colores verdes y rojos, con cenefas amarillas y verdes; una con flecadura de seda verde, de tres varas y media de largo, con un ave Fénix en el centro con una medida de una vara y dos tercios de ancho y otros elementos inciertos en blanco, azul y otros colores; otra más con el escudo de armas de la casa ducal en medio y cuatro más en sendas esquinas, con pérdidas — "unos despojos de guerra"- en las cenefas, y cuyas medias eran de dos varas y tres cuartas de largo por vara y tres cuartas de ancho.

Al inicio de 1617 existía otra alfombra de "campo carmesí, con unas flores azules, doradas y verdes, que tiene de largo seis varas y de ancho dos y tercia"; otra más de cinco varas y media por dos y tercia, también de color carmesí con unos lazos y hojas anchas verdes blancas, amarillas y azules; otra agujereada de cinco varas y dos tercios, por dos varas y media, carmesí, "que es hermana de la de arriba"; finalmente otra alfombra más "de las tres que entregó en Madrid el contador Bobadilla”. De igual modo, el duque adquirió otras piezas distintas de Alcaraz el 27 de febrero de $1617 .{ }^{31}$

Por su parte, cuando los duques de Arcos hicieron el traslado de su vivienda principal desde Marchena a Madrid en 1673, procedieron a realizar inventario de sus bienes para aclarar cuáles quedarían en el palacio andaluz y cuáles pasarían a la casa de la villa y corte. De acuerdo con dicho recuento, se hallaban

tres alfombras pequeñas, dos de seda y una de Alcaraz (...), otra alfombra de Alcaraz de cinco ruedas a cada lado, que son diez (...), otra alfonbra de Alcaraz de otras diez ruedas, cinco a cada lado (...), otra alfonbra de Alcaraz pequeña de tres ruedas (...), más una alfombra de Alcaraz rosa de tres baras y media, poco más o menos de ancho una bara y tres quartas, amarilla y colorada.

Aunque se registran un total de veinte alfombras, sólo se cita la procedencia de estas además de otras tres turcas, debiéndose añadir el dato de que en otro inventario se registró una alfombra "cairina", alusiones que denotan la relevancia de tales procedencias. ${ }^{32}$

Pocos años más tarde, el 18 de abril de 1680, fallecía en Madrid Ana María Velasco y de la Cueva, condesa de Siruela, tras lo cual se procedió a inventariar sus bienes. El 18 de mayo de 1680 Tomás de Pazos, maestro tapicero, se encargó de tasar los reposteros, tapices y alfombras de la condesa, entre las cuales destacaban de forma especial algunas elaboradas en la ciudad de Alcaraz:

- Primeramente una alfombra de Alcaraz blanca y negra, con ruedas en medio, ya usada, que tiene diez varas de largo y quatro y media de ancho, 1800 reales;

- más otra alfombra blanca y negra, de Alcaraz, de diez baras de largo y cinco de ancho, 1500 reales; ${ }^{33}$

- más otra alfombra de quatro baras y media de largo y tres de ancho cortada por medio, 200 reales; 
- más otra alfombra del mismo xénero, de quatro baras de largo y dos de ancho, 170 reales;

- más otra alfombra asimismo de Alcaraz también de luto, blanca y negra açul y amarillo, que tiene de largo siete baras y tres y media de ancho, 980 reales. $^{34}$

Por último, una información posterior que permanecía inédita delata la presencia de algunos de estos preciados bienes entre el patrimonio personal de los duques de Alba en la centuria del dieciocho. Vayamos a 1776. En noviembre de ese año fallecía Fernando de Silva y Álvarez de Toledo, XII duque de Alba, por lo que tras la prematura desaparición de su hijo Francisco de Paula, duque de Huéscar (1770), destinado a sucederlo, quedó por heredera su hija María del Pilar Teresa Cayetana de Silva y Álvarez de Toledo, nacida en 1762. La más célebre de las duquesas de la Casa de Alba - entre otras razones, por sus retratos debidos a Francisco de Goya-, había casado en enero de 1775 con un pariente cercano, José Álvarez de Toledo Osorio y Gonzaga, duque de Fernandina y marqués de Villafranca del Bierzo. El novio tenía diecinueve años; la novia, tan solo trece. ${ }^{35}$

La ceremonia nupcial se celebró en el palacio de la calle de Don Pedro de Madrid (en la actualidad, muy remodelado y sede de la Real Academia de Ingeniería). Durante la vida de José Álvarez de Toledo, esta casa fue engalanada profusamente y se convirtió en fastuoso palacio y el lugar donde vivieron durante varios años los cónyuges aristócratas, hasta que se trasladaron al recién estrenado palacio de Buenavista, hecho construir por el marido.

En 1796, poco tiempo después del fallecimiento del XIII duque (consorte) de Alba, se procedió a hacer inventario de los bienes de los palacios familiares de Madrid, tanto el de la Calle Don Pedro, como el de Buenavista, conocido por la familia como el "palacio del barrio del Barquillo". Una vez más, llama la atención la importancia concedida a las alfombras elaboradas en Alcaraz, las cuales aparecen inventariadas en primer lugar, por delante de otras registradas con otras procedencias, como un par de Madrid, varias turcas, alfombras de Hungría, piezas de moqueta francesa e inglesa, etc. ${ }^{36}$ Dados su diferente antigüedad y uso, las alfombras se hallaban en variados estados de conservación, y consta que fueron instaladas en distintos ámbitos del palacio de la calle de Don Pedro, pues el de Buenavista estuvo claramente peor dotado. De tal modo, en el primer y principal palacio hubo alfombras de Alcaraz destinadas al menos al gabinete de la duquesa, la sala de compañía de la duquesa y el despacho del duque. Por lo que se refiere a las alfombras que se hallaban en la calle de Don Pedro, estas son sus características: 


\begin{tabular}{|c|c|c|c|c|c|c|}
\hline \multirow{2}{*}{$\begin{array}{c}\begin{array}{c}\text { longitud } \\
\text { (varas) }\end{array} \\
\text { [equivalencia: } \\
\mathrm{cm}]\end{array}$} & \multirow{2}{*}{$\begin{array}{c}\text { anchura } \\
\text { (varas) } \\
\text { [equivalencia: } \\
\mathrm{cm}]\end{array}$} & \multirow{2}{*}{$\begin{array}{c}\text { superficie } \\
\text { (varas }^{2} \text { ) } \\
\text { [equivalencia: } \\
\mathrm{m}^{2} \text { ] }\end{array}$} & \multirow{2}{*}{ ubicación } & \multicolumn{2}{|c|}{ descripción } & \multirow{2}{*}{$\begin{array}{c}\text { valor } \\
\text { (reales) }\end{array}$} \\
\hline & & & & diseño & estado & \\
\hline $\begin{array}{c}\mathbf{6 , 2 5} \\
{[708,59 \mathrm{~cm}]}\end{array}$ & $\begin{array}{c}\mathbf{5 , 7 5} \\
{[480,64 \mathrm{~cm}]}\end{array}$ & $\begin{array}{c}\mathbf{3 5 , 9 3 7 5} \\
{\left[34,0578 \mathrm{~m}^{2}\right]}\end{array}$ & \multirow{2}{*}{$\begin{array}{c}\text { gabinete de la } \\
\text { duquesa }\end{array}$} & $\begin{array}{l}\text { fondo dorado, } \\
\text { fajas blancas, } \\
\text { cenefas } \\
\text { verdes }\end{array}$ & buen estado & 1221,29 \\
\hline $\begin{array}{c}6 \\
{[501,54 \mathrm{~cm}]}\end{array}$ & $\begin{array}{c}\mathbf{5 , 6 6} \\
{[473,67 \mathrm{~cm}]}\end{array}$ & $\begin{array}{c}\mathbf{3 3 , 9 6} \\
{\left[23,7567 \mathrm{~m}^{2}\right]}\end{array}$ & & $\begin{array}{l}\text { fondo } \\
\text { amarillo, con } \\
\text { cuadros y } \\
\text { adornos }\end{array}$ & $\begin{array}{l}\text { "bastante } \\
\text { maltratada" }\end{array}$ & 408 \\
\hline $\begin{array}{c}18 \\
{[1504,62 \mathrm{~cm}]}\end{array}$ & $\begin{array}{c}\mathbf{6 , 5} \\
{[543,33 \mathrm{~cm}]}\end{array}$ & $\begin{array}{c}117 \\
{\left[81,7512 \mathrm{~m}^{2}\right]}\end{array}$ & (desconocida) & $\begin{array}{l}\text { fondo verde, } \\
\text { con fajas } \\
\text { negras y } \\
\text { verdes, } \\
\text { cenefa } \\
\text { colorada con } \\
\text { adornos } \\
\end{array}$ & $\begin{array}{l}\text { "bastante } \\
\text { desgastada } \\
\text { y } \\
\text { deslucida" }\end{array}$ & 1872 \\
\hline $\begin{array}{c}\mathbf{1 5 , 5} \\
{[1295,64 \mathrm{~cm}]}\end{array}$ & $\begin{array}{c}\mathbf{6 , 5} \\
{[543,33 \mathrm{~cm}]}\end{array}$ & $\begin{array}{c}\mathbf{1 0 0 , 7 5} \\
{\left[70,3969 \mathrm{~m}^{2}\right]}\end{array}$ & $\begin{array}{c}\text { sala de } \\
\text { compañía de } \\
\text { la duquesa }\end{array}$ & $\begin{array}{l}\text { fondo } \\
\text { colorado, } \\
\text { estrellas } \\
\text { blancas, } \\
\text { cenefa verde } \\
\text { con adornos }\end{array}$ & $\begin{array}{l}\text { "bastante } \\
\text { usada y } \\
\text { manchada" }\end{array}$ & 1209 \\
\hline $\begin{array}{c}6 \\
{[501,54 \mathrm{~cm}]}\end{array}$ & $\begin{array}{c}\mathbf{5 , 2 5} \\
{[438,84 \mathrm{~cm}]}\end{array}$ & $\begin{array}{c}\mathbf{3 1 , 5} \\
{\left[22,0099 \mathrm{~m}^{2}\right]}\end{array}$ & $\begin{array}{l}\text { despacho del } \\
\text { duque }\end{array}$ & $\begin{array}{l}\text { dibujo de } \\
\text { solado blanco } \\
\text { y oro }\end{array}$ & (no consta) & 532 \\
\hline
\end{tabular}

Simultáneamente, las casas del barrio del Barquillo también contaban con alfombras y moquetas de orígenes diversos, entre ellas

vna alfombra de Alcaraz apolillada, deslucida, partida y unida por medio con varias composturas, su fondo encarnado, adornos y matices con cenefa; mide quatro varas y quarta de largo por tres de ancho, que hacen doce varas y tres quartas, $\mathrm{y}$, a seis reales vara, importa $76,17 .{ }^{37}$

Se trata, como vemos, de un conjunto en el que destaca la enorme longitud de dos alfombras (15,05 $\mathrm{m}$ y 12,95 $\mathrm{m}$, respectivamente), que, sin ser los más largos que se conocen, sí que resultan verdaderamente singulares por sus dimensiones. Sus medidas exceden con mucho lo acostumbrado, sobre todo de acuerdo con el tarifario de mercancías —o relación de precios máximos a que se debían vender diferentes productos- que se elaboró en 1628. Entre los precios señalados, se consignaron los correspondientes a las alfombras de Alcaraz. Aunque se tratase de una relación de valores alejada en el tiempo de las alfombras conservadas en los inmuebles de la Casa de Alba, nos sirve de referencia para conocer cuáles fueron los tipos de alfombra más difundidas en el comercio del siglo XVII, así como su valor monetario. ${ }^{38}$ Las tarifas se establecieron de acuerdo con el tamaño de las piezas, diferenciándose las de color (también denominadas floreadas) de las que se hacían en blanco y negro. 
Así se concreta un primer grupo de alfombras, de dos varas y media de largo, y vara y cuarta de ancho:

- las de diseño de tres ruedas y dibujos de jarras y pájaros en medio (60 reales).

- las de color, llamadas "floreadas" y "adamascadas" (70 reales).

- las blancas y negras, que se realizaban para uso de mujeres viudas (56 reales).

Las alfombras de tres varas y media de largo, y vara y dos tercios de ancho

- decoradas con diez ruedas, cada una de las cuales presentaba un ramilletero (120 reales).

- floreadas y adamascadas (132 reales).

Las de cuatro varas de largo y de dos de ancho

- las de color (210 reales)

- blancas y negras (200 reales).

Las piezas de cinco varas de largo y dos y media de ancho

- floreadas de colores (330 reales).

- blancas y negras (300 reales).

Las de seis varas de largo y tres de ancho,

- de color (50 ducados).

- blancas y negras (500 reales).

Las alfombras de siete varas de largo y tres y media de ancho

- de color (800 reales).

- blancas y negras (750 reales).

Las alfombras de ocho varas de largo, y cuatro de ancho

- de color (1 300 reales).

- blancas y negras (1 200 reales).

El mencionado tarifario también recogía el valor de otras piezas textiles de Alcaraz, como los reposteros de cama, descritos como "de dos varas y media de largo, y dos y tercia de cayda"; y las "carpetas de cama”, de dos tamaños, las almohadas "de alfombra", tanto de color como en blanco y negro.

\section{Rasgos tipológicos y decorativos}

A la vista de las descripciones que discurren a lo largo de la Edad Moderna, podemos establecer una evolución formal en el diseño de las alfom- 
bras. No obstante, ya en el paso del siglo XV al XVI se manifestó una gran creatividad en la factura de alfombras, mostrando todo tipo de arrequives, lo que se expresa en la combinación de las típicas ruedas (que en realidad entendemos eran más bien octógonos, si atendemos a las piezas que han sobrevivido) con elementos muy diversos. Entre ellos, se detectan motivos a modo de cordones "de San Francisco", abundantes en las cenefas, pero de los cuales no parece haber sobrevivido ningún ejemplo. Hay que suponer que estas figuras responden al empuje que experimentó el franciscanismo en el entorno de la reina Isabel, fenómeno evidenciado en la decoración de numerosas fachadas palaciegas de la época y que continuó durante el siglo XVI, como detecta Sánchez Ferrer en algunos ejemplos de la segunda mitad de dicha centuria. ${ }^{39}$

Las ruedas también se combinan con escritura cúfica árabe o con unos trazos que la imitan (pseudoárabe), pero irán cayendo en desuso, sobre todo una vez que se consagra la ortodoxia tridentina. ${ }^{40}$ Otros elementos que se asocian con las ruedas son "cruzeticas", cruces de San Andrés, de Calatrava (de las que hasta la fecha no teníamos constancia, al igual que sucede con las citadas cruces de San Andrés), lazos (escasamente documentados hasta el momento), losanges, árboles... También animales, tales como perros, osos, leones y puercos —esto es, jabalíes-, representándose en ocasiones algunos entre árboles, tal como se describe en una alfombra de Juana I y se aprecia en la de Medina de Pomar. En este sentido, conviene señalar que esta fauna responde a modelos iconográficos usados rutinariamente en los talleres en la medida en que no todas las especies son propias de la comarca alcaraceña.

En cuanto a los campos o fondos, se advierte cómo muy a principios del siglo XVI ya se empleaban los tonos anaranjados que en lo sucesivo se irán generalizando. Algunas alfombras son tan pintorescas, como la que, en el lote de 1501, presenta "ocho ruedas y el arraquive azul e colorado, e un torçal blanco e colorado, e al un cabo nueve puercos verdes e naranjados, e al otro leones e osos", y otra del mismo conjunto "de muchas lauores e lazos" y un intenso colorido, con un campo verde y "lauores amarillas e coloradas e azules, cercada con vnos ramos commo de yiedra negros e naranjados con unas florezicas blancas", con lazos blancos y rojos "a manera de letras moriscas" en una orla colorada. ${ }^{41}$ Este abundante colorido se vuelve a manifestar tres siglos más tarde en la colección de la casa de Alba.

En cambio, parece claro que en el siglo XVII entre las piezas de mayores dimensiones (a partir de cuatro varas de largo) se había estandarizado un tipo de manufactura que oscilaba entre las alfombras con flores de color y las que se realizaban en blanco y negro, algo más económicas y destinadas a mujeres viudas. Sólo las de menor tamaño permitían una mayor libertad en los dibujos, comprendiendo las clásicas ruedas unidas a otros motivos (jarrones, aves, flores, ramos...), si bien a medida que pasan los años, la geometría de las ruedas va a ir dando paso a los elementos vegetales. Nos hallamos bajo el triunfo iconográfico de la naturaleza muerta y ello se hace necesariamente extensible al arte mobiliario.

Por último, dada la naturaleza aristocrática de muchos de quienes encargaron la elaboración de las alfombras, en algunas de ellas hicieron constar motivos heráldicos o legendarios encaminados a dotar al linaje de una preeminencia y capital simbólico en la representación de su posición social. De ahí el Ave Fénix y las armas bordados en sendas piezas del palacio de los duques de Lerma. 


\section{Balance y reflexión}

En definitiva, toda esta escueta información no hace sino confirmar el verdadero valor que tuvieron las alfombras confeccionadas en Alcaraz en su día. Pretenden así estas líneas contribuir a mejorar el conocimiento de tales elementos suntuarios, ponderando su presencia y protagonismo en el entorno de los Reyes Católicos y en los palacios de algunas de las principales familias aristocráticas de la España de los Austrias, circunstancia esta que delata la importancia social de estos objetos. Ciertamente, la presencia de alfombras alcaraceñas en los espacios áulicos desde el siglo XV era un aspecto ya conocido, pero hasta la fecha solo se habían publicado noticias dispersas. Con este trabajo intentamos ofrecer una visión más completa de su presencia en las cámaras de los Reyes Católicos y de sus hijas e hijo, al tiempo que la complementamos con algún dato disperso y no recogido en las principales obras de referencia.

A falta de una documentación archivística local valiosa para nuestros propósitos, resulta difícil hacer un seguimiento de esta actividad textil en los núcleos de la comarca de Alcaraz, pero se nos revela toda una red de oficios (tejedores, tintoreros, hiladores, comerciantes...) que contribuyeron desde la Edad Media tardía a la configuración de un sólido sector económico en la ciudad al que además se vinculó una parte del sector ganadero, siempre tan protegido por las oligarquías alcaraceñas.

La llegada de los Reyes Católicos al poder supuso un hecho de enorme transcendencia para la manufactura y el comercio de alfombras en la tierra de Alcaraz y significó el inicio de un periodo de impulso que perduraría durante toda la Edad Moderna. La demanda de alfombras por parte de la realeza y del más elevado sector aristocrático, siempre mimetizándose en sus hábitos y modos a los de los reyes, inauguró una larga edad dorada en la confección de tales objetos en la comarca, con especial actividad no solo en la cabecera, sino en las pequeñas poblaciones de fuerte componente morisco, como fueron las que componían las vecinas encomiendas santiaguistas, en especial Liétor y Letur, sin que debamos descartar otros pueblos próximos.

Entendemos también con ello la especial valía de estas alfombras como canal continuado de afluencia monetaria en una comarca con una economía endémicamente maltrecha prácticamente desde los inicios de su andadura tras la conquista cristiana. Quien se vio más beneficiada en la ciudad fue la incipiente burguesía dueña de los telares, así como los grandes propietarios de reses ovinas, que proporcionaban la materia prima a sus talleres; no en vano, las oligarquías siempre primaron la ganadería frente a la expansión de cultivos. Por ello la confección de alfombras resultó un negocio tan próspero y duradero que marcó la vida económica de la comarca durante toda la Edad Moderna, en la cual las grandes familias del reino mantuvieron la inercia de compra de las lujosas piezas.

Por otra parte, la descripción de numerosas alfombras alcaraceñas de las épocas analizadas nos permiten mejorar nuestra percepción acerca de los cambios en los gustos de la realeza y las élites nobiliarias. La pujanza progresiva del blasón, la reducción de la escritura arábiga y de la geometría en favor del motivo vegetal, el aumento de la gama blanco-negro en la España de los Austrias, la solemnidad reservada a las piezas de grandes dimensiones y el 
correlativo anecdotismo de la decoración en las alfombras pequeñas, fueron clara tendencia en el devenir estético de dicha época.

\section{Apéndice documental}

S.l. 1504 , s.f.

Relación de las veinte alfombras de tipología de Alcaraz adquiridas en Granada el 20 de marzo de 1501 por Sancho de Paredes y Beatriz Cuello para la reina Isabel.

Archivo Fundación Tatiana Pérez de Guzmán El Bueno, CA.68-009/001 (Cuentas de Sancho de Paredes; Olim, 68-09, f. 250-251)

- una alhonbra de las de Alcaraz, con seys ruedas y dos medias, que tiene veynte palmos, e a los cabos vna lauor de unos cordones como de Sant Françisco azules e una orla como letras moriscas sobre canpo verde e unas arraquebes (sic, por arrequives) que parten las ruedas, el canpo de los cuales es azul.

- mas otra alhonbra de las de Alcaraz de ocho ruedas del mismo largo, e unos arraquebes en canpo azul e unas cruzeticas en los blancos y la orla de tres cruzeticas en canpo verde y al un cabo ocho astas naranjadas.

- mas otra alhonbra de las de Alcaraz que tiene veynte palmos y ocho ruedas y los arraquebes en canpo azul e unas cruzeticas amarillas y negras, y a los cabos unos cordones de Sant Françisco negros y colorados y unos manojos verdes.

- mas otra alhonbra de las de Alcaraz de otros veynte palmos, de ocho ruedas, que tiene el arraquive sobre azul e unas commo letras coloradas e negras e unos punticos en ellas amarillos, e a los cabos unas lauores verdes e amarillas con unas cruses en ellas.

- mas otra alhonbra de las de Alcaraz de otros veynte palmos, de seys ruedas enteras e dos medias que tiene el arraquive verde e naranjado con unos puntos negros, e a los cabos dos cordones commo de San Françisco asules escuros.

- mas otra alhonbra de las de Alcaraz de otros veynte palmos e ocho ruedas, que tiene el arraquive con el canpo azul vnas aspas de sant Andres blancos, e a los cabos unos arboles verdes e colorados.

- mas otra alhombra de las de Alcaraz de otros veynte palmos de otras ocho ruedas que tiene el arraquive en canpo azul con unas puntas verdes y negros, y a los cabos por orlas unas lisonjas (losanges) blancas y negras.

- mas otra alhombra de las de Alcaraz de otros veynte palmos e seys ruedas que tiene el arraquive verde e naranjado con unas aspas por el negras e a los cabos una lauor verde e negra e blanca.

- mas otra alhonbra de las de Alcaraz que tiene veynte palmos e ocho ruedas, y el arraquive azul e colorado, e un torçal blanco e colorado, e al un cabo nueve puercos verdes e naranjados e al otro leones e osos.

- mas otra alhonbra de las de Alcaraz que tiene veynte e çinco palmos e diez ruedas enteras e dos medias, e el arraquive azul e colorado con unas cruzeticas de Calatraua blancas, e a los cabos unos arboles colorados e verdes. 
- mas otra alhonbra de las de Alcaraz de veynte e çinco palmos, que tiene diez ruedas el arraquive azul e colorado, con unos puntos amarillos y negros e una orla verde e colorada, e al un cabo siete leones e al otro seys.

- mas otra alhonbra de las de Alcaraz de otros veynte e çinco palmos, de muchas ruedas pequeñas con unas cadenas alrededor amarillas y verdes, con una orla verde e colorada, con unos punticos blancos por ella.

- mas otra alhonbra de las de Alcaraz de otros veynte e çinco palmos con diez ruedas de lazos blancos e verdes e amarillos, que tiene el arraquive azul e colorado e amarillo e verde.

- mas otra alhonbra de las de Alcaraz de otros veynte e çinco palmos e diez ruedas, que tiene el arraquive azul e colorado y unos puntos negros por él y la orla colorada sobre canpo verde, y a los cabos siete leones.

- mas otra alhonbra de las de Alcaraz que tiene otros veynte e çinco palmos y otras diez ruedas y el arraquive azul y colorado con vnos puntos amarillos y negros, la orla morada e verde a manera de lazos, con unas asitas amarillas junto con la orla, y a los cabos unos arboles.

- mas otra alhonbra de las de Alcaraz que tiene treynta palmos en largo, de muchas lauores e lazos, el canpo sobre verde, e las lauores amarillas e coloradas e azules, cercada con vnos ramos commo de yiedra ${ }^{42}$ negros e naranjados con unas florezicas blancas, e por orla vnos lazos blancos y colorados a manera de letras moriscas, y la orla colorada commo de... (la descripción se interrumpe así)

- mas otra alhonbra de las de Alcaraz que tiene otros treynta palmos, de muchas ruedas pequeñas sobre canpo verde cerca<da $>$ de unos lazos blancos con unas lisonjas pequeñas, amarillas e coloradas, e a los cabos una labor commo oja de yedra azul e colorada.

- mas otra alhonbra de las de Alcaraz que tiene de largo otros treynta palmos y tiene ocho ruedas a manera de lazos amarillos e verdes sobre canpo colorado y alderredor un çerco verde e naranjado con unas aspitas commo de Sant Andres negras, e la vorla de unas cruzes coloradas e azules, e a los cabos unos ramos.

- mas otra alhonbra de las de Alcaraz del tamaño e lauores que la suso dicha.

- mas otra alhonbra de las de Alcaraz que tiene de largo quarenta palmos, e diez ruedas grandes y el arraquive de unos lazos azules, e a los cabos cada siete leones çercados de un cordon commo de San Françisco verdes y colorados y negros.

\section{NOTAS}

${ }^{1}$ Trabajo inscrito dentro del proyecto de investigación SBPLY/19/180501/000187 Ciudad, economía y territorio en Castilla-La Mancha durante la Baja Edad Media, aprobado por la Consejería de Educación, Cultura y Deportes de la Junta de Comunidades de Castilla-La Mancha y cofinanciado por el Fondo Europeo de Desarrollo Regional y adscrito a la Universidad de Castilla-La Mancha, a desarrollar entre 2020 y 2023.

${ }^{2}$ Dorothy G. Shepherd, "A fifteenth century Spanish carpet". Bulletin of the Cleveland Museum of Art 41, no. 8 (1954): 188-190; Sarah B. Sherrill, "The Islamic tradition in Spanish 
rug weaving: twelfth through seventeenth centuries", no. 3 (marzo 1974): 535; Cristina Partearroyo Lacaba, "Alfombras antiguas españolas", Congreso sobre arte textil e indumentaria: materias, técnicas y evolución (abril 2003): 73-117 [Recurso electrónico disponible en: https://www.ge-iic.com/wp-content/uploads/2006/07/cristina_partearroyo.pdf (consulta: septiembre 2021)] (sin paginación)

${ }^{3}$ C. Partearroyo Lacaba, "Alfombras antiguas españolas", Congreso sobre arte textil e indumentaria: materias, técnicas y evolución (abril 2003) (sin paginación).

${ }^{4}$ José Sánchez Ferrer, Alfombras de Alcaraz y de Liétor (Albacete: Instituto de Estudios Albacetenses, 2013). Este exhaustivo estudio adolece de una irresponsable edición y un número tan exiguo de ejemplares que prácticamente sólo es consultable por medios digitales, cuando su abultado contenido, su interés para públicos variados y su concepción visual merecían un tratamiento analógico y una mayor tirada.

${ }^{5}$ Para una bibliografía especializada y actualizada referida a las alfombras históricas de Alcaraz, véase J. Sánchez Ferrer, Alfombras de Alcaraz y de Liétor (Albacete: Instituto de Estudios Albacetenses, 2013), 421-430.

${ }^{6}$ Entre las numerosas obras en que José Luis Barrio Moya alude a la posesión de alfombras alcaraceñas, cabe citar: "Una interesante biblioteca jurídica madrileña del siglo XVII y otros bienes de don Cristóbal de Corcos, abogado de los reales consejos (1639)", Anuario Jurídico y Económico Escurialense, no. 37 (2004): 839-851; "Doña Ana María Velasco y de la Cueva, X Condesa de Siruela y el inventario de sus bienes (1680)", XXXV Coloquios Históricos de Extremadura (2006): 87-104; "El caballero murciano don Lucas López Hurtado de Angulo y su carta de dote (1668)" Murgetana, no. 116 (2007): 55-64; "El abogado navarro Don Antonio de Feloaga y Ozcoidi, Fiscal del Real Consejo de Indias durante el reinado de Felipe IV", Boletín de la Real Sociedad Bascongada de Amigos del País, no. 65 (2009): 667-688; "La biblioteca de don Juan de Arcaya, funcionario de Felipe IV en la Secretaría de Guerra (1663)", Cuadernos para investigación de la literatura hispánica, no. 36 (2011): 391408; "Doña Jerónima de Lara, una Dama navarra en el Madrid de Carlos II y el Inventario de sus bienes (1690)", Boletín de la Real Sociedad Bascongada de Amigos del País, no. 68 (2012): 203-220; "Don Juan Domingo del Solar y Toraya, un cántabro palentino funcionario de Carlos II en el Consejo de Indias", Publicaciones de la Institución Tello Téllez de Meneses, no. 85 (2014): 9-19.

7 José Luis Barrio Moya, "Doña Jerónima de Lara", "Doña Jerónima de Lara, una Dama navarra en el Madrid de Carlos II y el Inventario de sus bienes (1690)", Boletín de la Real Sociedad Bascongada de Amigos del País no. 68 (2012): 208.

${ }^{8}$ Gustavo Curiel Méndez, "Ajuares domésticos: Los rituales de lo cotidiano", en Antonio Rubial García (Coord.), La ciudad barroca (México: El Colegio de México - Fondo de Cultura Económica, 2005), 82.

${ }^{9}$ Aurelio Pretel Marín, "Alfombras de Alcaraz en casa de un hidalgo de principios del siglo XVI: El bachiller Juan Martínez Guerrero", Al-Basit, no. 64 (diciembre 2019), 6.

${ }^{10}$ Juan Ramírez de Lucas, "Notas para una historia de la artesanía de la Provincia de Albacete", Cuadernos de Estudios Manchegos, 4 (1951): 19.

${ }^{11}$ Antonio de la Torre (Ed.), Cuentas de Gonzalo de Baeza, tesorero de Isabel la Católica, I (Madrid: Consejo Superior de Investigaciones Científicas - Patronato Marcelino Menéndez Pelayo, 1955), 330.

${ }^{12}$ Aurelio Pretel Marín, "Notas pintorescas sobre las alfombras de Alcaraz en los comienzos del siglo XVI". Al-Basit, no. 0 (agosto 1975): 7.

${ }^{13}$ Archivo Fundación Tatiana Pérez de Guzmán El Bueno, CA.68-009/001 (Cuentas de Sancho de Paredes; Olim, 68-09, f. 245 y ss). Salvo que otra cosa se indique, las alfombras de época isabelina aparecen consignadas en esta fuente. 
${ }^{14}$ Según Covarrubias, paneles son "armas en los escudos en forma de coraçones".

${ }^{15}$ Archivo General de Simancas, Cámara de Castilla, Registro de Cédulas, Libros generales, 5, f. 252r-255r (Granada, 24-septiembre-1501); José Sánchez Ferrer, Alfombras de Alcaraz y Liétor (Albacete: Instituto de Estudios Albacetenses, 2013), 70.

${ }^{16}$ José Sánchez Ferrer, Alfombras de Alcaraz y Liétor (Albacete: Instituto de Estudios Albacetenses, 2013), 73, 231, 227. El número de inventario de la pieza del Museo Nacional de Artes Decorativas (Madrid) es 19.979.

${ }^{17}$ José Ferrandis, Datos documentales para la Historia del Arte español. III. Inventarios reales (Juan II a Juana la Loca) (Madrid: Consejo Superior de Investigaciones Científicas, 1943), 350. Cit. María del Cristo González Marrero, La casa de Isabel la Católica. Espacios domésticos y vida cotidiana (Ávila: Diputación Provincial - Institución Gran Duque de Alba, 2006), 143; José Sánchez Ferrer, Alfombras de Alcaraz y Liétor (Albacete: Instituto de Estudios Albacetenses, 2013): 296.

${ }^{18}$ Aurelio Pretel Marín, "Notas pintorescas sobre las alfombras de Alcaraz en los comienzos del siglo XVI", Al-Basit, no. 0 (agosto 1975): 8. Cit. José Sánchez Ferrer, Alfombras de Alcaraz y Liétor (Albacete: Instituto de Estudios Albacetenses, 2013): 70-73, 204. Según Pretel, algunas de estas alfombras llegaban a valer 5.000 maravedís.

${ }^{19}$ José Sánchez Ferrer, Alfombras de Alcaraz y Liétor (Albacete: Instituto de Estudios Albacetenses, 2013), 74 .

${ }^{20}$ William Stirling-Maxwell, The cloister life of the emperor Charles V (London: John C. Nimmo, 1891): 484. Podrían tratarse de las que se registran en José Sánchez Ferrer, Alfombras de Alcaraz y Liétor (Albacete: Instituto de Estudios Albacetenses, 2013), 76.

${ }^{21}$ Aurelio Pretel Marín, "Notas pintorescas sobre las alfombras de Alcaraz en los comienzos del siglo XVI”, Al-Basit, no. 0 (agosto 1975): 9-10.

${ }^{22}$ Paula Martínez Hernández, Financieros y gestores vascos en la corte castellana a fines de la edad Media: el tesorero Ochoa de Landa (Tesis Doctoral, Universidad del País Vasco, 2017), 436. ${ }^{23}$ F.J. Sánchez Cantón (Ed.) Archivo Documental Español. Inventarios reales. Bienes muebles que pertenecieron a Felipe II (Madrid: Real Academia de la Historia, 1959), 116-128. Reconociendo la variabilidad de las unidades de longitud, aceptamos para la vara una equivalencia de $83,59 \mathrm{~cm}$, mientras que el palmo corresponde a un cuarto de vara.

${ }^{24}$ José Sánchez Ferrer, Alfombras de Alcaraz y Liétor (Albacete: Instituto de Estudios Albacetenses, 2013), 77 (a partir de Ferrandis y Zarco Bacas).

${ }^{25}$ Archivo Histórico de Protocolos de Madrid, 6622, f. 502. En José Luis Barrio Moya, "Un documento sobre adquisiciones de Velázquez", Archivo Español de Arte, no. 195 (1976), 327. Cit. en Corpus velazqueño. Documentos y textos, I (Madrid: Ministerio de Educación, Cultura y Deportes - Dirección General de Bellas Artes y Bienes Culturales, 2000), 112, 321.

${ }^{26}$ Carlos Ayllón Gutiérrez, Inquisidores, conversos y cambio social. El Santo Oficio en tierras albacetenses (Albacete: Instituto de Estudios Albacetenses), 49.

${ }^{27}$ Se adquirió al mercader Alonso de Torres. Archivo General de Indias, Indiferente General, Registros, 426, libro 25, f. 90r-90v (Madrid, 10 de noviembre de 1570).

Archivo General de Indias, Indiferente General, Registros, 426, libro 25, f. 90R-90V

${ }^{28}$ María Concepción Quintanilla Raso, Nobleza y señoríos en el reino de Córdoba: la casa de Aguilar (siglos XIV y XV) (Córdoba: Caja de Ahorros, 1979), 325.

${ }^{29}$ Jerónimo Román, Repúblicas del Mundo. Tercera parte (Salamanca: 1595), 166 v. ${ }^{\circ}$

${ }^{30}$ José Antonio Casillas García, El monasterio de San Blas de la villa de Lerma: una historia inmóvil (Salamanca: San Esteban, 2008), 297.

${ }^{31}$ Estos detalles, en Luis Cervera Vera, Bienes muebles en el palacio ducal de Lerma (Madrid:

Castalia, 1967), 34 y 105-106.

${ }^{32}$ Archivo Histórico de la Nobleza, Osuna, C. 1624, nº 13. 
${ }^{33}$ Sobre esta alfombra, cabe la posibilidad de que se encargara en aquellas fechas, pues la tipología en blanco y negro iba destinada a las viudas.

${ }^{34}$ A lo referido se añadían "dos reposteros de Salamanca con armas de la Casa (...) más siete tapices antiguos, de gorrillas, de estofa entrefina, rotos y viexos, de cinco anas de caída”. José Luis Barrio Moya, "Doña Ana María Velasco y de la Cueva, X Condesa de Siruela y el inventario de sus bienes (1680)", XXXV Coloquios Históricos de Extremadura (2006): 87-104.

${ }^{35}$ El matrimonio se había concertado en 1772. Véase: María del Mar Nicolás Martínez, "Galas y regalos para una novia, a propósito de la boda de María del Pilar Teresa Cayetana de Silva, duquesa de Alba", Congreso Internacional Imagen y Apariencia, Murcia, 2009. https://digitum.um.es/digitum/bitstream/10201/44227/1/CongresoImagen127.pdf (consulta: enero 2022). ${ }^{36}$ Archivo de la Casa Ducal de Medina Sidonia, leg. 5118. ("Inventario y tasación de los bienes que han quedado en la casa de la calle de Don Pedro y en el barrio del Barquillo por fallecimiento de José Álvarez de Toledo, XV [sic] duque de Alba")

${ }^{37}$ Ibidem.

${ }^{38}$ Tassa de los precios a que se han de vender las mercaderias y otras cosas de que no se hizo mencion en la primera Tassa y Reformacion que aora se ha hecho (Madrid: Imp. Juan González, 1628), f. 22r. La primera tasa, establecida por el Consejo de Castilla, dio lugar a la Pragmática de 13 de septiembre de 1627. Al surgir algunas dudas, al año siguiente se realizaron correcciones y aclaraciones a las que corresponden estas tarifas relativas a las alfombras de Alcaraz.

39 José Sánchez Ferrer, Alfombras de Alcaraz y Liétor (Albacete: Instituto de Estudios Albacetenses, 2013), 381.

40 José Sánchez Ferrer, Alfombras de Alcaraz y Liétor (Albacete: Instituto de Estudios Albacetenses, 2013), 237-241.

${ }^{41}$ Archivo Fundación Tatiana Pérez de Guzmán El Bueno, CA.68-009/001, f. 250 r-v.

${ }^{42}$ En hiedra hay una y sobrepuesta a la h inicial, lo que denota las dudas en la grafía.

Fecha de recepción: 13 de septiembre de 2021

Fecha de revisión: 1 de octubre de 2021

Fecha de aceptación: 16 de enero de 2022 